\title{
OPEN Bacterial synthesis of PbS nanocrystallites in one-step with L-cysteine serving as both sulfur source and capping ligand
}

\author{
Shiping Wei ${ }^{1,2 \bowtie}, C^{2}$ Guo $^{2}$, Lijuan Wang ${ }^{3}$, Jiangfeng $X u^{3} \&$ Hailiang Dong ${ }^{1}$
}

The green bacterial biosynthesis of lead sulfide nanocrystallites by L-cysteine-desulfurizing bacterium Lysinibacillus sphaericus $\mathrm{SH} 72$ was demonstrated in this work. Nanocrystals formed by this bacterial method were characterized using the mineralogical and morphological approaches. The results revealed that the microbially synthesized $\mathrm{PbS}$ nanocrystals assume a cubic structure, and are often aggregated as spheroids of about $105 \mathrm{~nm}$ in size. These spheroids are composed of numerous nanoparticles with diameter $5-10 \mathrm{~nm}$. Surface characterization of the bacterial nanoparticles with FTIR spectroscopy shows that the L-cysteine coats the surface of $\mathrm{PbS}$ nanoparticle as a stabilizing ligand. The optical features of the PbS nanocrystallites were assessed by UV-Vis spectroscopy and PL spectroscopy. The maximum absorption wavelength of the bacterial PbS particles occurs at $240 \mathrm{~nm}$, and the photoluminescence emission band ranges from 375 to $550 \mathrm{~nm}$. The band gap energy is calculated to be $4.36 \mathrm{eV}$, compared to $0.41 \mathrm{eV}$ for the naturally occurring bulk PbS, with this clear blue shift attributable to the quantum size effect.

Nanocrystalline materials refer to solid materials with crystal grain sizes in the range of 1-100 nm. Compared with their naturally occurring bulk materials, the surfaces of nanograins exhibit comparatively high energy arising from the large volume fraction of molecules and atoms residing in the grain boundaries. These properties confer special electrical and optical attributes to those materials ${ }^{1,2}$, imparting great potential industrial applications to the nanocrystalline materials ${ }^{3,4}$. Lead sulfide $(\mathrm{PbS})$ is a typical IV-VI group semiconductor material. It has a sizable exciton Bohr radius $(18 \mathrm{~nm})$ and a rather narrow bulk band gap $(0.41 \mathrm{eV})$. These properties gave $\mathrm{PbS}$ a good quantum confinement in the nano-sized structures ${ }^{5}$, thus providing promising potential applications in infrared detectors ${ }^{6}$, solar cells ${ }^{7}$, gas and biosensors ${ }^{8,9}$, and photonic crystals ${ }^{10}$.

Currently, successful synthesis of $\mathrm{PbS}$ nanoparticles has utilized three different strategies: physical, chemical or biological approaches ${ }^{4,11,12}$. Generally, metallic $\mathrm{Pb}^{13}, \mathrm{PbO}^{14,15}, \mathrm{PbNO}_{3}{ }^{5}$ and $\left(\mathrm{CH}_{3} \mathrm{COO}\right)_{2} \mathrm{~Pb}^{16}$ can act as the lead sources to synthesize $\mathrm{PbS}$ nanoparticles, while the sulfur sources can be provided by $\mathrm{H}_{2} \mathrm{~S}^{13}, \mathrm{Na}_{2} \mathrm{~S}^{15}, \mathrm{Na}_{2} \mathrm{~S}_{2} \mathrm{O}_{3}{ }^{16}$, cysteine $^{17}$, thiourea ${ }^{5}$ and (TMS) ${ }_{2} \mathrm{~S}^{14}$. The physical and chemical approaches towards $\mathrm{PbS}$ nanoparticle production are superior in production rate and capacity ${ }^{16,18,19}$. To synthesize different shapes of nanosized PbS particles, various ligands serve as the stabilizers to coat the surfaces of PbS nanoparticles $1^{1,20,21}$. The nature of capping ligands can markedly influence the electro-optical properties of $\mathrm{PbS}$ nanoparticles ${ }^{22}$. However, the physical and chemical approaches require a high capital cost, large energy consumption, and usually generate hazardous wastes leading to pollution issues ${ }^{4,23}$. Moreover, the nanoparticles synthesized by those two approaches are regarded as less biocompatible, resulting in their limitations towards biological and medical applications $\mathrm{s}^{4,24}$.

Considering the drawbacks of the physical and chemical synthesis approaches, recently-developed microbial synthesis of the nanoparticles has attracted interest in the nanoscience and nanotechnology communities and now is preferred approach ${ }^{25-29}$. Previous investigations have demonstrated that heavy metal tolerant microorganisms can induce nanoparticle formation either extracellularly or intracellularly ${ }^{4,30-32}$. Different microorganisms

\footnotetext{
${ }^{1}$ State Key Laboratory of Biogeology and Environmental Geology, China University of Geosciences, Beijing 100083, China. ${ }^{2}$ School of Marine Sciences, China University of Geosciences, Beijing 100083, China. ${ }^{3}$ School of Materials Science and Technology, China University of Geosciences, Beijing 100083, China. ${ }^{\varpi}$ email: weishiping@ cugb.edu.cn
} 


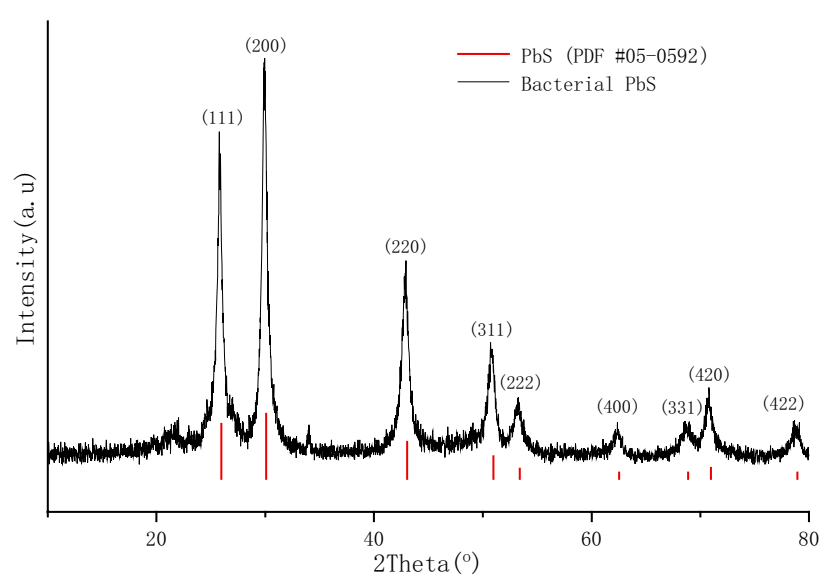

Figure 1. XRD diffraction pattern of bacterial $\mathrm{PbS}$ formed by L. sphaericus $\mathrm{SH} 72$.

use different mechanisms to synthesize nanoparticles ${ }^{4,23,33}$. In this study, an L-cysteine desulfurizing bacterium, was used to synthesize PbS nanoparticles. Lysinibacillus sphaericus SH72 was previously having been shown to produce cysteine desulfhydrase to catalyze the conversion of L-cysteine to pyruvate, hydrogen sulfide and $\mathrm{ammonia}^{34}$. During this synthesis process, biogenic hydrogen sulfide immediately reacts with $\mathrm{Pb}^{2+}$ to form $\mathrm{PbS}$ in the liquid medium, which obviates the danger of toxic $\mathrm{H}_{2} \mathrm{~S}$ release to the environment. Moreover, L-cysteine not only serves as the sulfur source for the $\mathrm{PbS}$ nanoparticle formation but also acts as a stabilizer to coat the $\mathrm{PbS}$ nanoparticle surface, achieving a one-step green synthesis of nanocrystallites of $\mathrm{PbS}$.

\section{Materials and methods}

Bacterial strain and media. A strain of L-cysteine desulfurizing bacteria Lysinibacillus sphaericus SH72 was previously isolated from marine sediments from Beidaihe, China ${ }^{34}$. The medium was used for bacterial synthesis of $\mathrm{PbS}$ particles by L. sphaericus SH72 was made with (in $\mathrm{g} / \mathrm{L}$ ) containing yeast extract 3.0, beef extract 5.0 , peptone 5.0, and $\mathrm{NaCl} 2.0$, with $\mathrm{pH}$ adjusted to 7.2 by $\mathrm{NaOH} / \mathrm{HCl}$. After autoclaving for $30 \mathrm{~min}$ at $121^{\circ} \mathrm{C}$, the medium was then supplemented with the filter sterilized L-cysteine $2.0 \mathrm{~g} / \mathrm{L}$ and $\left(\mathrm{CH}_{3} \mathrm{COO}\right)_{2} \mathrm{~Pb} \cdot 3 \mathrm{H}_{2} \mathrm{O} 0.2 \mathrm{~g} / \mathrm{L}$.

Bacterial synthesis and collection of PbS nanoparticles. L. sphaericus $\mathrm{SH} 72$ was inoculated into $150 \mathrm{~mL}$ of sterilized liquid medium held in $500 \mathrm{~mL}$ Erlenmeyer flasks. The flask was sealed with a cotton plug and incubated at $28^{\circ} \mathrm{C}$, with agitation provided by a rotary shaker at $120 \mathrm{rpm}$. The culture was incubated with continuous shaking for $5 \mathrm{~d}$ to allow $\mathrm{PbS}$ nanoparticle formation. The PbS nanoparticles were collected by centrifugation at $5000 \mathrm{rpm}$ for $15 \mathrm{~min}$ and then underwent three washes with chloroform to remove the bacterial cell debris, followed by three thorough washes with distilled water. The purified nanoparticles were then air dried for further analyses.

Characterization. Phase structure of the purified nanoparticles was characterized with a Bruker D2 PHASER X-ray diffractometer (XRD) using $30 \mathrm{kV}, 10 \mathrm{~mA}$ and scanned from $2 \theta$ of 10 to 80, with a scanning rate of $0.02 \%$ s. Morphological observations of the nanoparticles were performed with an FEI Quanta 200F scanning electron microscope (SEM). For transmission (TEM) and high-resolution transmission electron microscopy (HRTEM) observations, the purified bacterial nanoparticles were suspended in water. After ultrasonication, the aqueous suspensions of bacterial nanoparticles were dropped on a carbon-coated copper grid until the solvent evolved was completely dried. The copper grid was then mounted in a TEM-FEI tecnai-F20 instrument, coupled with an Oxford energy-dispersive X-ray spectrometer (EDXS) for chemical analysis. TEM micrograph images were taken and SAED (selected area electron diffraction) patterns were acquired under a $200 \mathrm{kV}$ accelerating voltage. The bacterial nanoparticle surface was characterized by Fourier transform infrared spectroscopy (FTIR, Nicolet iS10 FTIR). The FTIR spectrum was obtained with a resolution of $4 \mathrm{~cm}^{-1}$ in the $4000-400 \mathrm{~cm}^{-1}$ region. The optical properties of the PbS nanocrystallites were measured on a Hitachi U3900 UV-Vis spectrophotometer from 150 to $800 \mathrm{~nm}$, and an F-4600 FL photoluminescence spectrophotometer.

\section{Results and discussion}

Structural and morphological characteristics of the bacterial PbS nanocrystallites. The XRD pattern of the bacterial PbS nanoparticles is depicted in Fig. 1. The diffraction peaks at $2 \theta$ angles of 25.78, 29.90, $42.92,50.73,53.38,62.37,68.61,70.60$ and 78.81 degrees index to a cubic PbS mineral phase (JCPDS \#05-0592). The peak broadening is indicative of smaller dimensions in nanoparticles. The average crystallite sizes are calculated to be $9.2 \mathrm{~nm}$ according to Scherrer's equation ${ }^{35}$. Previous study showed that L. sphaericus SH72 is an L-cysteine desulfurizing bacterium. It can produce cysteine desulfhydrase, by which to catalyze the conversion of $\mathrm{L}$-cysteine to pyruvate, hydrogen sulfide and ammonia ${ }^{34}$. The hydrogen sulfide released from $\mathrm{L}$-cysteine immediately reacts with $\mathrm{Pb}^{2+}$ to form $\mathrm{PbS}$ mineral in the liquid medium. 

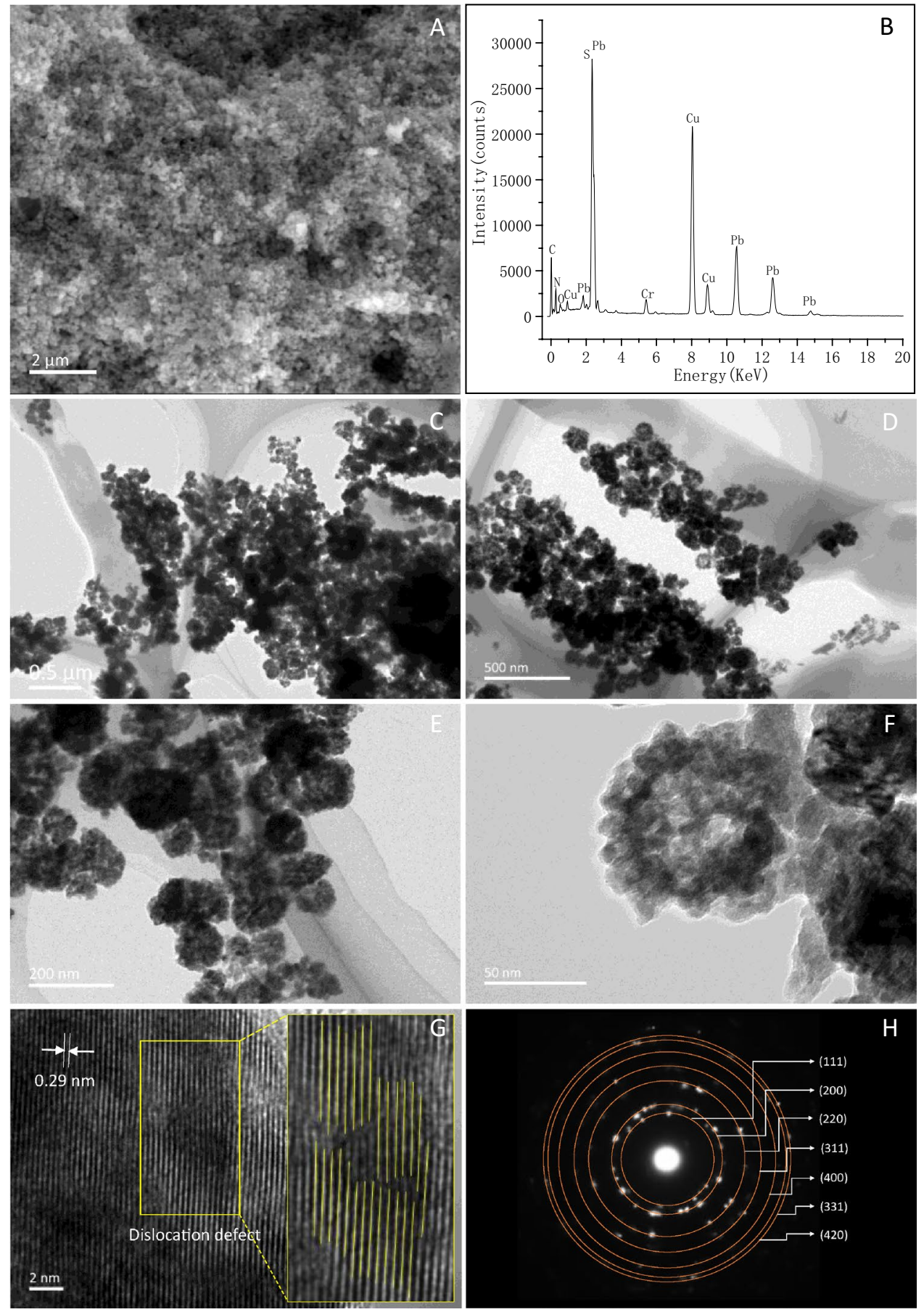

Figure 2. SEM (A), EDXS (B), TEM (C-F), HRTEM (G) and SAED (H) characterizations of the bacterial PbS nanoparticles. The $\mathrm{Cu}$ and $\mathrm{Cr}$ peaks in $(\mathbf{B})$ came from the TEM grid. The yellow rectangle zones in $(\mathbf{G})$ show a linear dislocation defect in the bacterial $\mathrm{PbS}$ nanocrystal.

The SEM image shows that the particles occur as spheroids (Fig. 2A). The EDXS spectrum shows that the chemical composition of the bacterial particles is mainly composed of $\mathrm{Pb}$ and $\mathrm{S}$, which yields a $\mathrm{Pb}: \mathrm{S}$ ratio of about 0.9:1 (Fig. 2B). The minor elements of $\mathrm{C}, \mathrm{N}$ and $\mathrm{O}$ are also present in the bacterial particles, suggesting that certain organic molecules probably coat the bacterial $\mathrm{PbS}$ nanoparticles ${ }^{11,21}$.

Upon a closer examination of the spheroids by TEM (Fig. 2C-F), the spheroids are present as globular aggregates of about $105 \mathrm{~nm}$ in size (Fig. 2C-E), which consist of numerous nanoparticles ranging in size 5-10 nm (Fig. 2E). The spherically shaped aggregates of the PbS particles synthesized by L. sphaericus SH72 are apparently different from those PbS particles synthesized by yeasts Rhodosporidium diobovatum, Torulopsis sp and the bacterium Rhodobacter sphaeroides ${ }^{2630,36}$, in which the PbS particles are virtually monodispersed spherical 


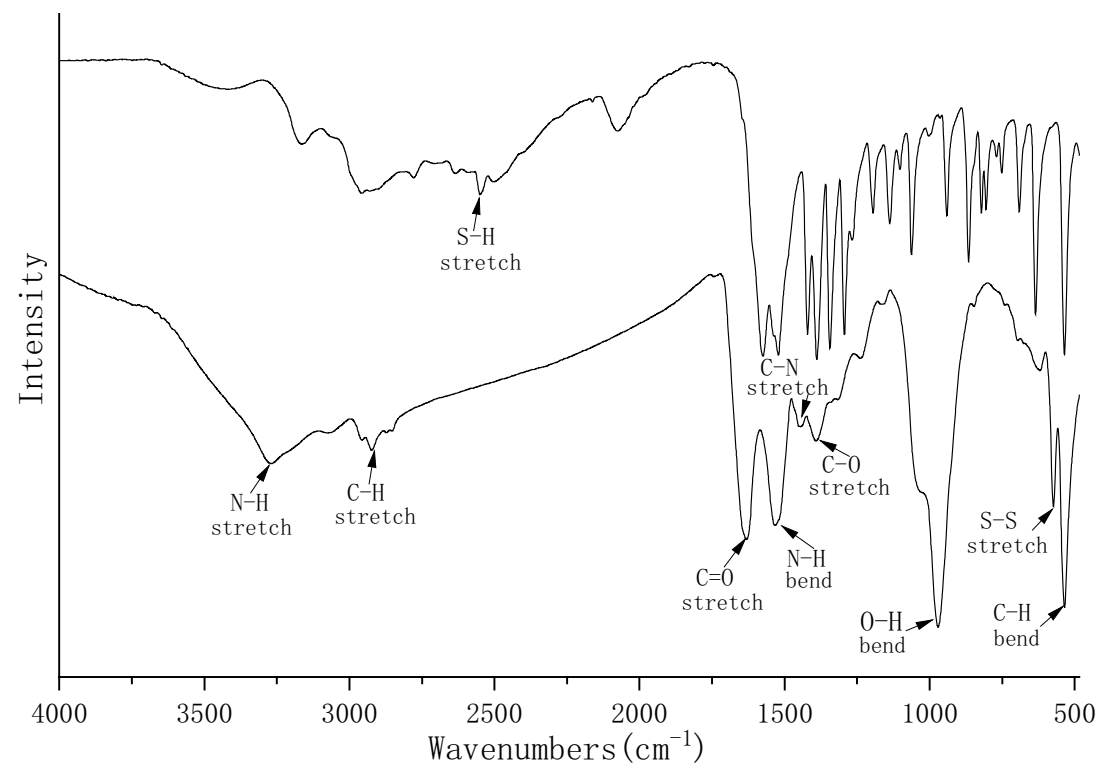

Figure 3. FTIR spectra recorded for L-cysteine (top) and the bacterial PbS nanoparticles (bottom).

nanoparticles. However, previous reports have shown that the morphology of chemically synthesized $\mathrm{ZnS}$ particles with cysteine caps is unaggregated and has a uniform shape and size ${ }^{37}$.

HRTEM and SAED analyses were performed to confirm the observed XRD results (Fig. 2G,H). The HRTEM micrographs of an individual bacterial $\mathrm{PbS}$ nanocrystal show a lattice spacing of $0.29 \mathrm{~nm}$, well matched with the (200) planes of a cubic PbS structure (Fig. 2G) ${ }^{35,36}$, and the formation of a linear dislocation defect went through the crystal was also observed in the bacterial PbS nanocrystal (Fig. 2G). The corresponding SAED pattern shows a set of discontinuous spots, forming concentric rings (Fig. $2 \mathrm{H}$ ) that indicate a random orientation of the $\mathrm{PbS}$ nanocrystals ${ }^{15,19}$. The seven rings can be ascribed to Miller indices of the cubic PbS phase (111), (200), (220), (311), (400), (331), and (420) (Fig. 2H). The HRTEM and SAED analyses on the structure of the bacterial PbS nanocrystals are congruent with the XRD data.

Optical properties of the bacterial PbS nanocrystallites. FTIR spectroscopic measurement was performed to reveal the bacterial $\mathrm{PbS}$ nanoparticles' surface coating of organic molecules (Fig. 3). It gives two absorption peaks at $3269 \mathrm{~cm}^{-1}$ and $2923 \mathrm{~cm}^{-1}$, which arise from the $\mathrm{N}-\mathrm{H}$ and C-H stretching vibrations, respectively. The absorption peaks at $1631 \mathrm{~cm}^{-1}, 1442 \mathrm{~cm}^{-1}$, and $1392 \mathrm{~cm}^{-1}$, are attributed to $\mathrm{C}=\mathrm{O}, \mathrm{C}-\mathrm{N}$, and $\mathrm{C}-\mathrm{O}$ stretching vibrations, respectively. A bending vibration of $\mathrm{N}-\mathrm{H}$ was observed at $1532 \mathrm{~cm}^{-1}$. The $573 \mathrm{~cm}^{-1}$ peak shows a vibration stretching of an S-S bond. The FTIR spectrum of L-cysteine shows a typical S-H vibrational band appearing at $2555 \mathrm{~cm}^{-1}$. However, this was not observed once cysteine is associated with the bacterial nanoparticles, indicating cleavage of the S-H bond. Instead, S-S bond formation was observed between the $\mathrm{L}$-cysteine molecules and the PbS nanoparticles. Previous studies have shown that cysteine could bind to PbS, $\mathrm{ZnS}$ and silver nanoparticles through a thiolate linkage ${ }^{20,37-39}$, serving as the stabilizing ligand to suppress the agglomeration of numerous particles ${ }^{11,21}$.

The UV-Visible spectrum of the bacterial PbS nanoparticles shows that a peak at 205-250 nm was observed (Fig. 4). Compared with the absorption coefficient of the bulk PbS at $3020 \mathrm{~nm}^{40}$, the bacterial PbS nanoparticles exhibit a significant blue shift. This is indicative of distinct quantum confinement arising from the reduction in particle dimensions. The optical band gap $\left(\mathrm{E}_{\mathrm{g}}\right)$ of the bacterial $\mathrm{PbS}$ nanoparticles is calculated according to the equation of $\alpha h \gamma=A\left(h \gamma-E_{g}\right)^{1 / 2}$ ( $\alpha$ is absorption coefficient, $h$ is Plank's constant, $\gamma$ is the incident photon frequency, $\mathrm{A}$ is absorbance), the result indicates that band gap of the bacterial nanoparticles is $4.36 \mathrm{eV}$, demonstrating a distinct $0.41 \mathrm{eV}$ blue shift of the band gap for the naturally occurring $\mathrm{PbS}^{35}$.

Figure 5 shows the excitation and photoluminescence (PL) spectra of the bacterial $\mathrm{PbS}$ nanoparticles. It is observed that the emission bands occur over a broad wavelength range of 375-550 $\mathrm{nm}$, and the emission peaks of the as-prepared bacterial $\mathrm{PbS}$ nanoparticles remain stable under excitation at different wavelengths. To further investigate the stability of the bacterial $\mathrm{PbS}$ nanoparticles, a storage of bacterial $\mathrm{PbS}$ nanoparticles for eight months were performed UV-Vis and PL spectra analyses, it shows that the corresponding absorbance spectra peak maxima wavelength and intensity have not been changed. Previous studies have shown that the defect-related luminescence often occurs in the inorganic crystals ${ }^{41-44}$. As Fig. $2 \mathrm{G}$ shows, a linear dislocation defect was observed in the bacterial $\mathrm{PbS}$ nanocrystals, which is inferred for the mechanism of luminescence. However, the process and mechanism by which dislocations form during the bacterial $\mathrm{PbS}$ crystal growth need to be further studied. 

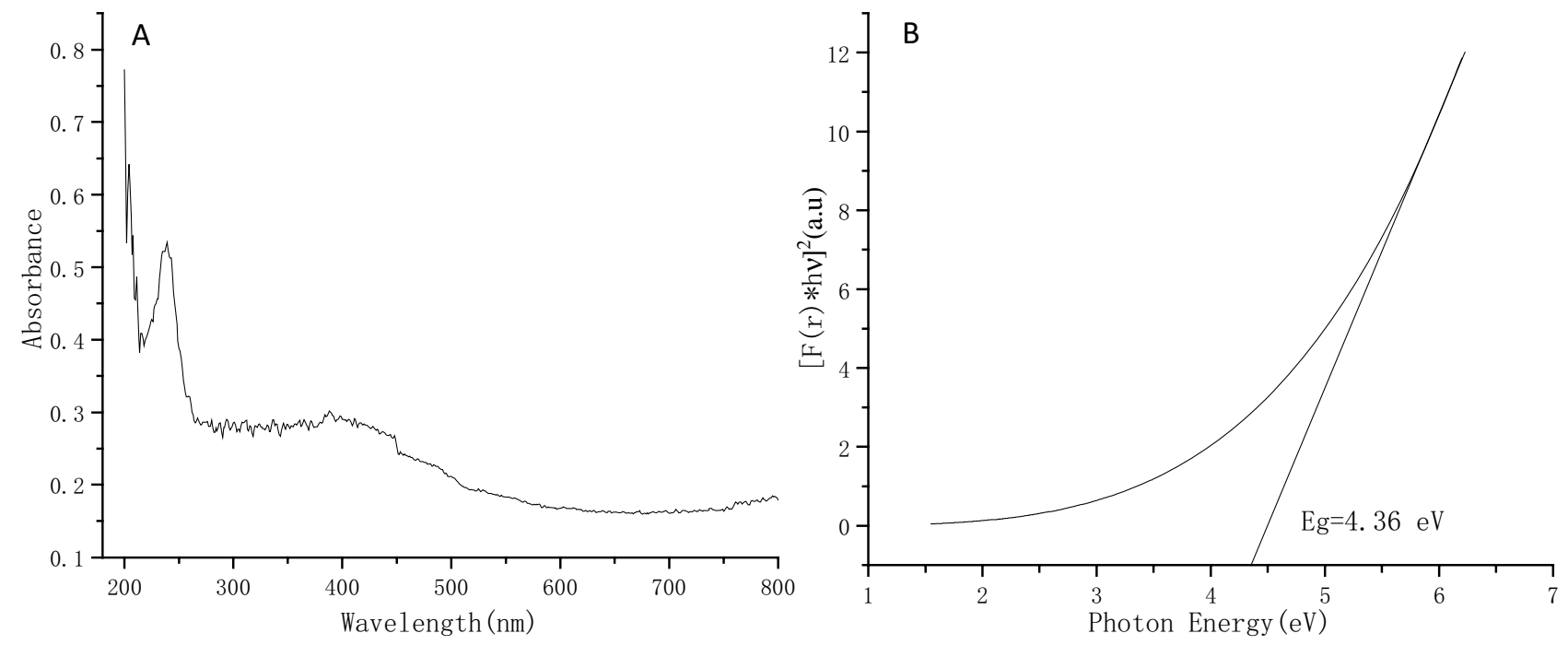

Figure 4. UV-Vis spectrum (A) and band gap plot (B) of the bacterial $\mathrm{PbS}$ nanoparticles.

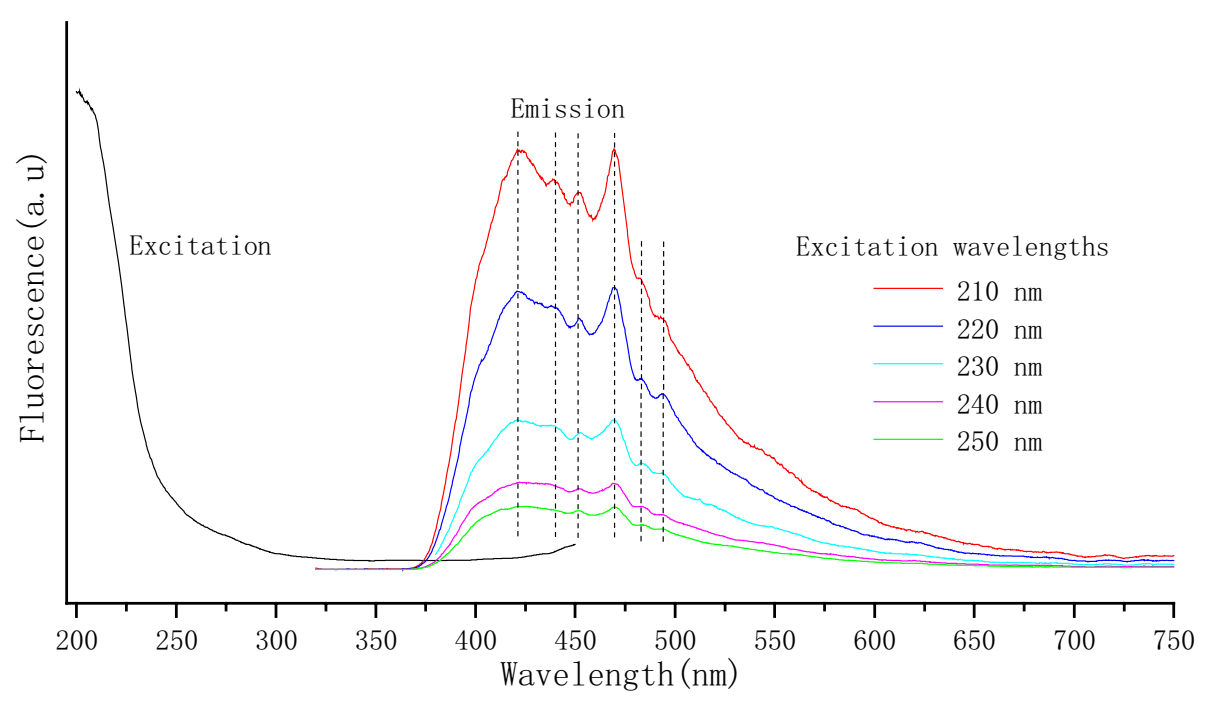

Figure 5. Photoluminescence (PL) excitation and emission spectra of the bacterial PbS nanoparticles.

\section{Conclusion}

In this study, it has been demonstrated that L. sphaericus SH72 could synthesize PbS nanocrystallites with $\mathrm{L}$-cysteine serving as the sulfur source as well as the coating ligand. TEM observation shows that the PbS nanocrystallites exhibit globular aggregations in size of about $105 \mathrm{~nm}$, which consist of numerous nanoparticles with dimentions ranging from 5 to $10 \mathrm{~nm}$. XRD and electron diffraction patterns confirm the bacterial nanocrystals form as cubic structures of PbS. Characterization of the bacterial nanoparticles by FTIR indicates that L-cysteine coats the nanoparticle surfaces as a stabilizing agent. The UV-Vis and PL spectra show a significant blue shift and an increased bandgap as compared to bulk PbS, with the increase attributable to its quantum confinement. This one-step green synthesis of nanocrystallites by an L-cysteine -desulfurizing bacterium has important advantages over other biosynthetic methods and promising potential applications in the area of semiconductor materials.

Received: 20 July 2020; Accepted: 21 December 2020

Published online: 13 January 2021

\section{References}

1. Suryanarayana, C. Structure and properties of nanocrystalline materials. Bull. Mater. Sci. 17, 307-346 (1994).

2. Suryanarayana, C. Nanocrystalline materials. Int. Mater. Rev. 40, 41-64 (1995).

3. Holzinger, M., Goff, A. L. \& Cosnier, S. Nanomaterials for biosensing applications: a review. Front. Chem. 2, 63 (2014).

4. Hosseini, M. R. \& Sarvi, M. N. Recent achievements in the microbial synthesis of semiconductor metal sulfide nanoparticles. Mater. Sci. Semicond. Process. 40, 293-301 (2015). 
5. Obaid, A. S., Mahdi, M. A., Hassan, Z. \& Bououdina, M. Characterization of nanocrystalline PbS thin films prepared using microwave-assisted chemical bath deposition. Mater. Sci. Semicond. Proc. 15, 564-571 (2012).

6. Pentia, E., Pintilie, L., Matei, I., Botila, T. \& Pintilie, I. Combined chemical-physical methods for enhancing IR photoconductive properties of PbS thin films. Infrared Phys. Technol. 44, 207-211 (2003).

7. Hosokawa, H. et al. Solution-processed intermediated-band solar cells with lead sulfide quantum dots and lead halide perovskites. Nat. Commun. 10, 43 (2019).

8. Fu, T. Research on gas-sensing properties of lead sulfide-based sensor for detection of $\mathrm{NO}_{2}$ and $\mathrm{NH}_{3}$ at room temperature. Sens. Actuators B Chem. 140, 116-121 (2009).

9. Sonawane, N., Gurav, K. V., Ahire, R. R., Kim, J. H. \& Sankapal, B. R. CdS nanowires with PbS nanoparticles surface coating as room temperature liquefied petroleum gas sensor. Sensor. Actuators A Phys. 216, 78-83 (2014).

10. Barth, C. et al. Increased fluorescence of $\mathrm{PbS}$ quantum dots in photonic crystals by excitation enhancement. Appl. Phys. Lett. 111, 031111 (2017).

11. Sadovnikov, S. I., Gusev, A. I. \& Rempel, A. A. Nanostructured lead sulfide: synthesis, structure and properties. Russ. Chem. Rev. 85, 731-758 (2016).

12. Ealias, A. M. \& Saravanakumar, M. P. A review on the classification, characterization, synthesis of nanoparticles and their application. IOP Conf. Ser. Mater. Sci. Eng. 263, 03201 (2017).

13. Chen, J. H., Chao, C. G., Ou, J. C. \& Liu, T. F. Growth and characteristics of lead sulfide nanocrystals produced by the porous alumina membrane. Surf. Sci. 22, 5142-5147 (2007).

14. Zherebetskyy, D. et al. Hydroxylation of the surface of PbS nanocrystals passivated with oleic acid. Science 344, 1380-1384 (2014).

15. Meng, W. et al. Mechanochemical synthesis of lead sulfide (PbS) nanocrystals from lead oxide. Powder Technol. 347, 130-135 (2019).

16. Ni, Y. et al. A novel aqueous-phase route to prepare flower-shaped PbS micron crystals. J. Cryst. Growth 262, 399-402 (2004).

17. Petean, I., Tomoaia, G. H., Horovitz, O., Mocanu, A. \& Tomoaia-Cotisel, M. Cysteine mediated assembly of gold nanoparticles. J. Optoelectron. Adv. M. 10, 2289-2292 (2008).

18. Mafuné, F., Kohno, J., Takeda, Y. \& Kondow, T. Dissociation and aggregation of gold nanoparticles under laser irradiation. J. Phys. Chem. B 105, 9050-9056 (2001).

19. Sadovnikov, S. I. \& Gusev, A. I. Chemical deposition of nanocrystalline lead sulfide powders with controllable particle size. J. Alloys Compd. 586, 105-112 (2014).

20. Sperling, R. A. \& Parak, W. J. Surface modification, functionalization and bioconjugation of colloidal inorganic nanoparticles. Philos. Trans. R. Soc. A 368, 1333-1383 (2010).

21. Saran, R. \& Curry, R. J. Lead sulphide nanocrystal photodetector technologies. Nat. Photonics 10, 81-92 (2016).

22. Garcia-Gutierrez, D. F. et al. Influence of the capping ligand on the band gap and electronic levels of PbS nanoparticles through surface atomistic arrangement determination. ACS Omega 3, 393-4035 (2018).

23. Xin, B., Huang, Q., Chen, S. \& Tang, X. High-purity nanoparticles ZnS production by a simple coupling reaction process of biological reduction and chemical precipitation mediated with EDTA. Biotechnol. Prog. 24, 1171-1177 (2008).

24. Naahidi, S. et al. Biocompatibility of engineered nanoparticles for drug delivery. J. Control. Release 166, 182-194 (2013).

25. Li, X., Xu, H., Chen, Z. S., \& Chen, G. Biosynthesis of nanoparticles by microorganisms and their applications. J. Nanomater. 2011, Article ID 270974 (2011).

26. Seshadri, S., Saranya, K. \& Kowshik, M. Green synthesis of lead sulfide nanoparticles by the lead resistant marine yeast Rhodosporidium diobovatum. Biotechnol. Prog. 27, 1464-1469 (2011).

27. Hussain, I., Singh, N. B., Singh, A., Singh, H. \& Singh, S. C. Green synthesis of nanoparticles and its potential application. Biotechnol. Lett. 38, 545-560 (2016).

28. Korbekandi, H., Iravani, S. \& Abbasi, S. Production of nanoparticles using organisms. Crit. Rev. Biotechnol. 29, 279-306 (2009).

29. Roy, S., Das, T. K., Maiti, G. P. \& Basu, U. Microbial biosynthesis of nontoxic gold nanoparticles. Mater. Sci. Eng. B Adv. 203, 41-51 (2016).

30. Kowshik, M., Vogel, W., Urban, J., Kulkarni, S. K. \& Paknikar, K. M. Microbial synthesis of semiconductor PbS nanocrystallites. Adv. Mater. 14, 815-818 (2002).

31. Narayanan, K. B. \& Sakthivel, N. Biological synthesis of metal nanoparticles by microbes. Adv. Colloid Interface Sci. 156, 1-13 (2010).

32. Priyanka, U. et al. Biologically synthesized $\mathrm{PbS}$ nanoparticles for the detection of arsenic in water. Int. Biodeterior. Biodegrad. 119, 78-86 (2017).

33. Iravani, S. Bacteria in nanoparticles synthesis: current status and future prospects. Int. Sch. Res. Notices 2014, Article ID 359316 (2014).

34. Guo, C., Liu, B., Bian, J. \& Wei, S. Diversity and characterization of L-cysteine desulfurizing bacteria isolated from marine sediments in Beidaihe. Microbiol. China 46, 1582-1589 (2019).

35. Kripal, R., Rudowicz, C. \& Tripathi, U. M. Spectroscopic study of $\mathrm{Mn}^{2+}$ doped PbS nanocrystals. Appl. Magn. Reson. 50, 785-795 (2019).

36. Bai, H. J. \& Zhang, Z. M. Microbial synthesis of semiconductor lead sulfide nanoparticles using immobilized Rhodobacter sphaeroides. Mater. Lett. 63, 764-766 (2009).

37. Ankireddy, S. R. \& Kim, J. Selective detection of dopamine in the presence of ascorbic acid via fluorescence quenching of InP/ZnS quantum dots. Int. J. Nanomed. 10, 113-119 (2015).

38. Khan, M. M., Kalathil, S., Lee, J. \& Cho, M. H. Synthesis of cysteine silver nanoparticles by electrochemically active biofilm and their antibacterial activities. Bull. Korean Chem. Soc. 33, 2592-2596 (2012).

39. Upadhyay, L. S. B. \& Verma, N. Dual immobilization of biomolecule on the glass surface using cysteine as a bifunctional linker. Process Biochem. 49, 1139-1143 (2014)

40. Sathyamoorthy, R. \& Kungumadevi, L. Facile synthesis of PbS nanorods induced by concentration difference. Adv. Powder Technol. 26, 355-361 (2015).

41. Leach, A. D. P. et al. Defect luminescence from wurtzite $\mathrm{CuInS}_{2}$ nanocrystals: combined experimental and theoretical analysis. J. Phys. Chem. C 120, 5207-5212 (2016).

42. Ge, K. et al. Defect-related luminescent mesoporous silica nanoparticles employed for novel detectable nanocarrier. ACS Appl. Mater. Interfaces 7, 10905-10914 (2015).

43. Chizhik, A. M. et al. Imaging and spectroscopy of defect luminescence and electron-phonon coupling in single $\mathrm{SiO}_{2}$ nanoparticles. Nano Lett. 9, 3239-3244 (2009).

44. Li, Q. \& Wang, G. T. Spatial distribution of defect luminescence in GaN nanowires. Nano Lett. 10, 1554-1556 (2010).

\section{Acknowledgements}

This research was supported by Funds of Oil and Gas Survey, China Geological Survey (GZH201400308). We thank James Hurley at Virginia Polytechnic Institute and State University for making a critical reading and revision of this paper. 


\section{Author contributions}

S.W. designed the study and wrote the manuscript. C.G. performed the bacterial PbS nanoparticle collection. L.W. and J.X. performed characterizations of the bacterial $\mathrm{PbS}$ nanocrystallites. H.D. performed the revision and editing of this manuscript.

\section{Competing interests}

The authors declare no competing interests.

\section{Additional information}

Correspondence and requests for materials should be addressed to S.W.

Reprints and permissions information is available at www.nature.com/reprints.

Publisher's note Springer Nature remains neutral with regard to jurisdictional claims in published maps and institutional affiliations.

(c) (i) Open Access This article is licensed under a Creative Commons Attribution 4.0 International License, which permits use, sharing, adaptation, distribution and reproduction in any medium or format, as long as you give appropriate credit to the original author(s) and the source, provide a link to the Creative Commons licence, and indicate if changes were made. The images or other third party material in this article are included in the article's Creative Commons licence, unless indicated otherwise in a credit line to the material. If material is not included in the article's Creative Commons licence and your intended use is not permitted by statutory regulation or exceeds the permitted use, you will need to obtain permission directly from the copyright holder. To view a copy of this licence, visit http://creativecommons.org/licenses/by/4.0/.

(C) The Author(s) 2021 